\title{
Management and Reduction of Chemical Nitrogen Consumption in Agriculture
}

\author{
Abedin Zafari ${ }^{1 *}$, Mohammad Hossein Kianmehr ${ }^{2}$ \\ ${ }^{1}$ Department of Agrotechnology, College of Abouraihan, University of Tehran, Tehran, Iran; ${ }^{2}$ Department of Agrotechnology, Col- \\ lege of Abouraihan, University of Tehran, Tehran, Iran. \\ Email: ${ }^{*}$ abedinzafari@ut.ac.ir
}

Received September $19^{\text {th }}, 2012$; revised November $15^{\text {th }}, 2012$; accepted December $10^{\text {th }}, 2012$

\begin{abstract}
Nitrogen is an effective material for improving the crop production. There is a big concern about rising chemical nitrogen usage as fertilizer in soil, because some forms of nitrogen absorbs in soil and causes an increase of environment and water pollution and decrease fertilizer efficiency. Composted cow manure is an important resource of organic nitrogen which improves the soil conditions. However, low density of composted cow manure and inconstant nutrient content are two factors that limit the application of composted cow manure. The densification technology is an effective solution for both problems. In this research first the capability of single screw extruder for production of fertilizer pellets including composted cow manure and nitrogen fertilizer was studied and then the effect of fertilizer pellet on the reduction of chemical nitrogen consumption was evaluated. The response of basil plants was determined in three treatments: $T_{1}$ control (no fertilizer), $T_{2}$ (nitrogen fertilizer) and $T_{3}$ (pellet). The results showed that pelletization can be used as a proper method for slow-release nitrogen fertilizer; enhance nitrogen uptake and reducing the chemical nitrogen consumption. The results also showed that all basil responses (chlorophyll content, total weight, leaves weight, root weight and leaf area) were significantly affected by application of $\mathrm{N}$ fertilizer and pellet. While maximum recorded parameters were observed with application pellet.
\end{abstract}

Keywords: Compound Fertilizer; Pellet; Densification; Compost; Slow-Release; Nitrogen

\section{Introduction}

Iran is the sixteenth largest country in the world with an area of more than 160 million hectares and its cultivated area is about 15 million hectares. Substantial growth in the use of chemical nitrogen $(\mathrm{N})$ fertilizer in Iran since the 1980s has provided significant economic and social benefits, including higher farm incomes, improved food consumption and the maintenance of national food security. Iran is now one of the largest consumers of $\mathrm{N}$ fertilizer. Nitrogen input is essential for high crop yields, but an excess use of $\mathrm{N}$ fertilizer cannot promise a substantial increase in crop productivity. Too much $\mathrm{N}$ fertilizer results in diminishing crop returns [1] and leads to diminished environmental quality and human well-being $[2,3]$. Excess $\mathrm{N}$ fertilizer use and runoff causes eutrophication in waterways which threatens human, animal and plant health.

Current usage of $\mathrm{N}$ fertilizer per unit crop area in Iran is high, but yield is lower than of some other countries. There are many strategies to improve fertilizer use efficiency. Many researchers have already studied on yield

\footnotetext{
${ }^{*}$ Corresponding author.
}

crop to evaluate some methods such as use of nitrogen sources fertilizers (encapsulated urea, granular oxamide and oxamid powder), placement techniques, split application of $\mathrm{N}$ fertilizers and nitrification inhibitors [4-7].

Fertilizers including livestock manure may be used for the crop production as a substitute of the chemical fertilizers. In Iran the total amount of livestock manure produced each year has now reached 100 million tons. The nitrogen content of this manure has been estimated at 7.5 million tons. Compost made from livestock manure provides a stable organic matter that improves the physical, chemical, and biological properties of soils [8,9], thereby enhancing soil quality and crop production $[10,11]$. The nitrogen concentration in compost is found in stable compounds in the organic matter. The nitrogen compounds remain in the soil, available for uptake by the plant roots over a long period of time, greatly reducing the threat of water pollution and eutrophication.

The composted manure is very bulky, its nutrient value is low and its nutrient composition is highly variable compared to chemical fertilizers. For this reasons the use of composts in agricultural remains low. An effective solution is to apply densification technology. 
Densification increases the bulk density of biomass from an initial bulk density of $40-200 \mathrm{~kg} \cdot \mathrm{m}^{-3}$ to a final bulk density of $600-1200 \mathrm{~kg} \cdot \mathrm{m}^{-3}$ [12-15]. Thus, densification of compost could reduce the costs of transportation, handling and storage [16,17] and adjusting the nutrient content by adding required materials. There are two kinds of pelleting machine available in the world which shape composted livestock manure into pellets. One kind is disk pelleter for dry material and the other one is extruder type for wet material [18]. In an extruder, the raw material is compressed by a screw or a piston through a die to form compacted particles, often of cylindrical shape. The diameter of extrusion products may range from 5 to $100 \mathrm{~mm}$.

The use of composted manure in addition to reducing chemical fertilizer consumption is a strategy for livestock manure management. The main objective of this study is to evaluate the potential of pelletization process to production compound fertilizer pellet from mixture of urea and composted cow manure and improve fertilizer use efficiency.

\section{Materials and Methods}

\subsection{Samples Preparation}

The study was carried out during the 2010-2012 at the Experimental Laboratory and Farm of College of Abouraihan, University of Tehran, Iran. Manure samples that were used as feedstock materials, were obtained from animal husbandry in the suburb of Tehran. Before being used for pellet production, the samples were stored in the laboratory at $25^{\circ} \mathrm{C}$ for a period of three months for decayed manure samples and complete composting process. Before pelleting, the samples were ground using a hammer mill with $0.3 \mathrm{~mm}$ screen.

\subsection{Pellet Production}

A laboratory scale pellet extruder was used to manufacture the pellets in this study. The pellet fertilizers were produced by mixing $\mathrm{N}$ fertilizer and composted cow manure with $1: 1$ ratio $(50 \% \mathrm{~N}$ from urea and $50 \%$ composted cow manure). Before pelleting, the moisture content of compost and urea grinds was adjusted to $35 \%$ (wet basis) by adding certain amount of tap water and mixed at room temperature for two minutes. No steam conditioning was used and no external binding agents were added in any of the pelleting experiments. The produced pellets have $6 \mathrm{~mm}$ diameter and their lengths varying between 8 to $20 \mathrm{~mm}$ (Figure 1).

\subsection{Chemical Composition}

A chemical analysis of the compost and pellets was conducted by chemical analytical laboratory (University of

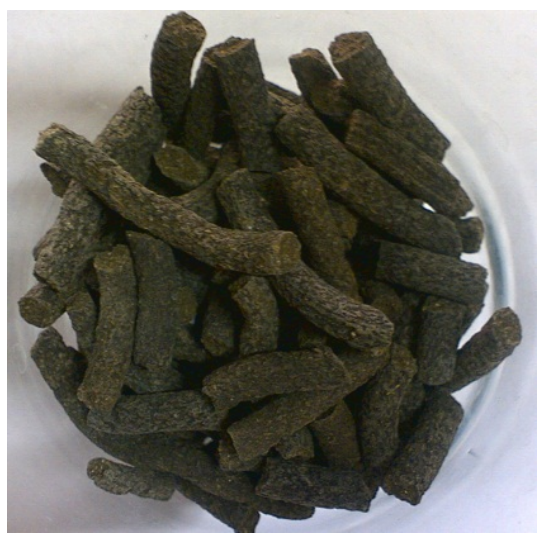

Figure 1. Fertilizer pellet including composted cow manure and $\mathbf{N}$ fertilizer.

Tehran). The analysis included the determination of protein, ash, fat, neutral detergent fiber (NDF), acid detergent fiber (ADF), lignin and starch. The nitrogen content was determined by using kjeldahl nitrogen apparatus. All experiments were carried out in triplicate.

\subsection{Electron Photography}

The electron photography method with electron microscope (XL30 model of Scanning Electron Microscopy (SEM) electron microscope) was used to identify the binding mechanism the particles of compost and $\mathrm{N}$ fertilizer. Electron photography carried out two months after pellet production.

\subsection{Greenhouse Evaluation of Fertilizer Pellet}

Experiments were conducted in a greenhouse at Tehran University in order to evaluate the effects of treatments in controlled conditions. Basil (Ocimum basilicum) seeds were disinfected with sodium hypochlorite $5 \%$ and planted in pots $(20 \mathrm{~cm}$ diameter and $30 \mathrm{~cm}$ hight) equally. The pots were poured with a mixture of clay, loam and sandy soil (Table 1). Cultivation and irrigation period was ten week and twice a week respectively. Throughout the cultivation period weeds were controlled manually and no herbicide toxin was used. Experimental design was carried out in a completely randomized design with three treatments including $\mathrm{T}_{1}$ (control, no fertilizer and compost manure), $\mathrm{T}_{2}$ ( $\mathrm{N}$ fertilizer) and $\mathrm{T}_{3}$ (fertilizer pellet). A constant value of fertilizer $(200 \mathrm{~kg} / \mathrm{ha})$ was added to soil of pots in $T_{2}$ and $T_{3}$. All experiments for each treatment were carried out in triplicate. Data were analyzed by using the analysis of variance (ANOVA) and Duncan's multiple tests at the 0.01 level procedures in SAS statistical software package.

\subsection{Evaluation of Plant Responses}

At the end of cultivation period the chlorophyll (Chl) 
Table 1. Some physical characteristics of mixed soil.

\begin{tabular}{cc}
\hline Charactristic & Value \\
\hline Sand $(\%)$ & 65 \\
Silt $(\%)$ & 15 \\
Clay $(\%)$ & 20 \\
EC $(\mathrm{dS} / \mathrm{m})$ & 1.6 \\
PH & 6.5 \\
Soil texture & Sandy clay loam \\
\hline
\end{tabular}

status, leaf area, fresh weight of root, stem and leaf was measured.

In photosynthesis, antenna pigments in leaf chloroplasts absorb solar radiation, and through resonance transfer the resulting excitation is channeled to the reaction centre pigments, which release electrons and set in motion the photochemical process. The chlorophylls, Chla and $\mathrm{Chlb}$, are the most important of these pigments, and are thus virtually essential for the oxygenic conversion of light energy to the stored chemical energy that powers the biosphere. Much of leaf nitrogen is incorporated in chlorophyll, so quantifying $\mathrm{Chl}$ content gives an indirect measure of nutrient status [19]. In this research the Chl content was measured using spectroscopy method. For the extractions, glass centrifuge vials containing $7 \mathrm{ml}$ dimethyl sulphoxide DMSO were preheated to $65^{\circ} \mathrm{C}$ in a water bath. Chl was extracted from three disks (each $3.038 \mathrm{~cm}^{2}$; approx. $100 \mathrm{mg} \mathrm{f}$. wt total) from each leaf sample. In preliminary trials, we found that extraction at $65^{\circ} \mathrm{C}$. was complete within $15-20 \mathrm{~min}$ and no loss of Chl occurred in the heated DMSO during the first hour; we therefore ran our extractions for $30 \mathrm{~min}$ When the extractions were complete, samples were removed from the water bath and each graduated vial was topped up to exactly $10 \mathrm{ml}$ with DMSO using a Pasteur pipette; $3 \mathrm{ml}$ of each extract were then transferred to disposable polystyrene cuvettes with a reported standard deviation between cuvettes of $< \pm 0.005$ extinction units, and a transmission between 600 and $700 \mathrm{~nm}$ of $85 \%$ or better (catalogue 14-385-985, Fisher Scientific, Pittsburgh, PA, USA). The spectrophotometer (range $200-1100 \mathrm{~nm}$, spectral bandwidth $5 \mathrm{~nm}$, wavelength accuracy $\pm 1 \mathrm{~nm}$, and wavelength setting repeatability of $\pm 0.3 \mathrm{~nm}$; model U-1100, Hitachi Ltd., Tokyo, Japan), was calibrated to zero absorbance using a blank of pure DMSO. Absorbance of both blank and sample were measured at 645 and $663 \mathrm{~nm}$. The elapsed time between removal from the water bath and completion of spectrophotometer measurements was in the order of $20 \mathrm{~min}$. The $\mathrm{Chl}$ concentration of the extract calculated from these equations:

$$
\begin{aligned}
& \operatorname{Chla}\left(\mathrm{gl}^{-1}\right)=0.0127 \mathrm{~A}_{663}-0.00269 \mathrm{~A}_{645} \\
& \operatorname{Chlb}\left(\mathrm{gl}^{-1}\right)=0.0229 \mathrm{~A}_{645}-0.00468 \mathrm{~A}_{663} \\
& \text { tot } \operatorname{Chl}\left(\mathrm{gl}^{-1}\right)=0.0202 \mathrm{~A}_{645}+0.00802 \mathrm{~A}_{663} .
\end{aligned}
$$

In order to measuring the leaves area, the area of all leaf of each stem measured using leaf area meter (Area Meter, Am 200, Bioscientific Ltd.) and the average recorded.

The total weight and weight of root and leaves of plants were measured using an electronic balance (KERN and Sohn $\mathrm{GmbH}$, Germany) with an accuracy of $0.01 \mathrm{gr}$.

\section{Results and Discussion}

\subsection{Chemical Composition}

The chemical compositions of composted cow manure and pellet fertilizer are presented in Table 2. Among the chemical components, the presence of protein and lignin may enhance the pelleting property of biomass powders. The presence of lignin in feed material enhances the binding characteristics of densified pellets [20,21]. Protein also plays a major role as a binding agent between different particles during compaction. During densification, the material experiences the combined effect of shear, heat, residence time and water resulting in partial denaturation of protein in the biomass. Wood reported that partial denaturation during processing may positively affect the hardness and durability of the pellets [22]. The lignin, protein and starch are natural binders that can improve biomass densification [23].

\subsection{Electron Photography}

The SEM photo of composted cow manure pellet is shown in Figure 2. These photos illustrate the structure of compost that can be used to recognize the layout structure of the urea particles between particles of compost in compound fertilizer pellet. Figures $\mathbf{3}$ and $\mathbf{4}$ show the SEM photos of compound fertilizer pellets. The compost was made up of overlapping layers and urea particles located on layers surface of compost as bright spots (Figure 3). The urea particles with $68 \mathrm{~nm}$ size were placed between compost particles.

Table 2. Chemical compositions of composted cow manure and pellet fertilizer.

\begin{tabular}{ccc}
\hline Composition & \multicolumn{2}{c}{ Dry mamater $(\%)$} \\
\hline PH & Compost & Pellet \\
\hline EC (ms/cm) & 8.59 & 8.23 \\
Nitrogen & 4.79 & 7.75 \\
Phosphorus & 1.21 & 24.7 \\
Potassium & 0.075 & \\
NDF & 1.02 & \\
ADF & 63.4 & \\
Cellulose & 48.4 & \\
Hemicellulose & 31.4 & \\
Lignin & 15 & \\
Starch & 17 & \\
Fat & 5.2 & \\
Protein & 3.21 & \\
Ash & 18.12 & \\
& 17.4 & \\
\hline
\end{tabular}




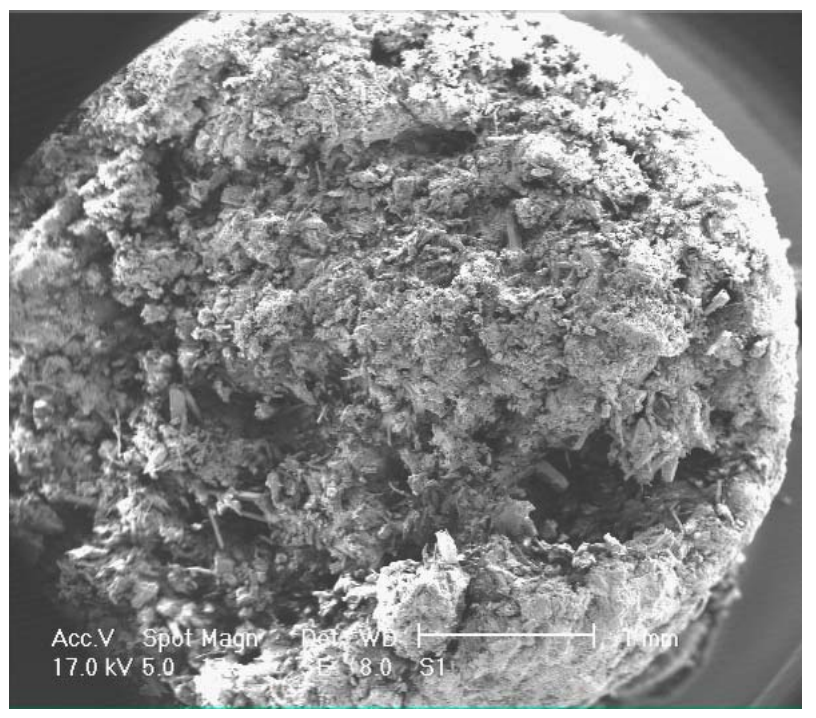

Figure 2. SEM picture of composted cow manure.
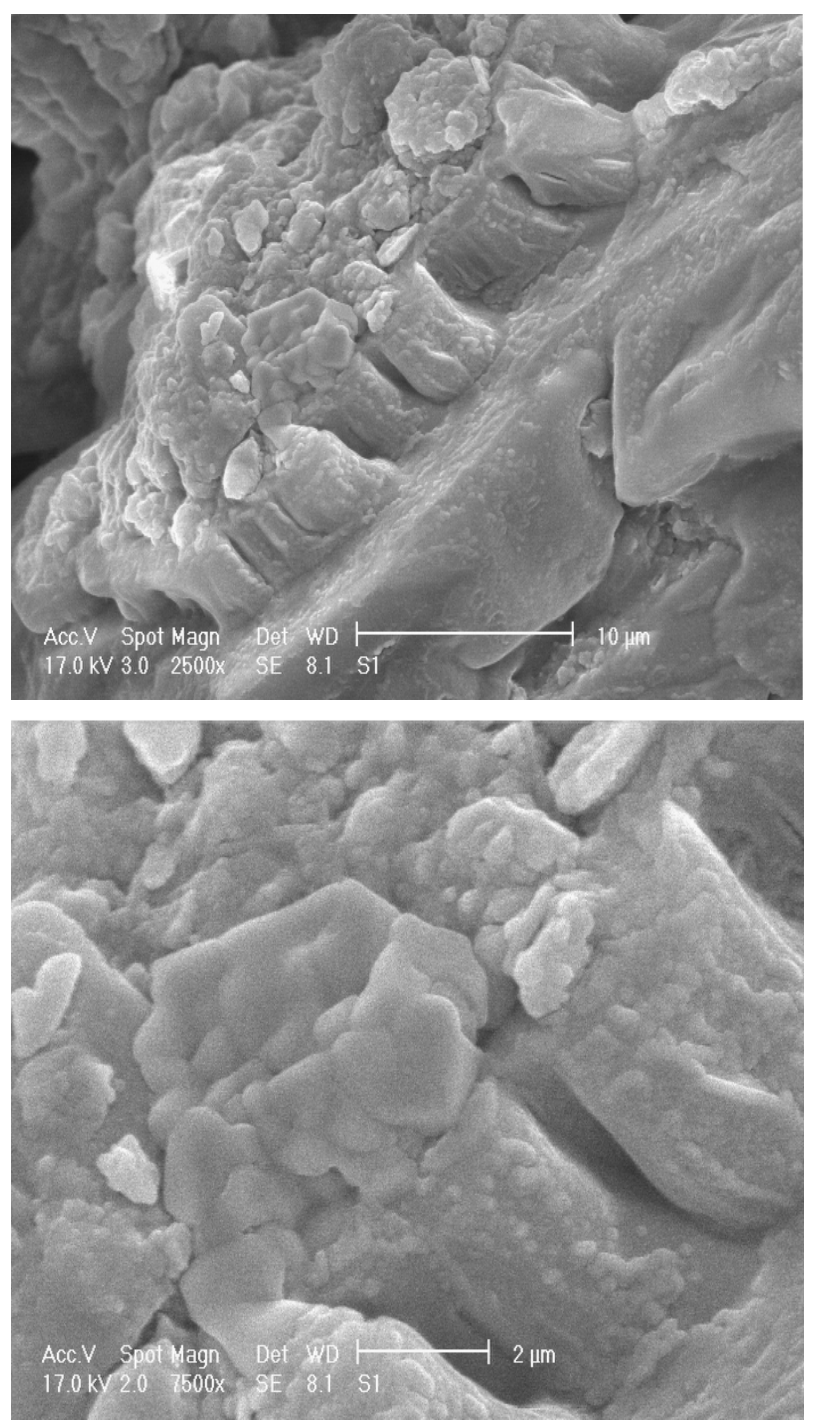

Figure 3. SEM pictures of compound fertilizer pellets.
The important binding mechanisms in biomass densification are formation of solid bridge, attraction forces between solid particles and mechanical interlocking bonds $[24,25]$. The SEM images showed that the bonding between particles was created mainly through solid bridges.

Due to the application of high pressures and temperature, solid bridges may be developed by diffusion of molecules from one particle to another at the points of contact. Solid bridges may also be formed between particles due to crystallization of some ingredients, chemical reaction, hardening of binders and solidification of melted components. The presence of lignin, hemicelluloses, starch and protein as the natural binders are important to form solid bridge [26]. During the densification process, fibers, flat-shaped particles, and bulky particles can interlock or fold about each other resulting in interlocking bonds. The formation of solid bridge and mechanical interlocking bonds between compost and urea particles are shown in Figure 4.

\subsection{Plant Responses}

The results indicate that plant $\mathrm{Chl}$ content was significantly affected by deferent treatments. The comparison of treatments' means revealed that maximum Chl (1.2 $\mathrm{mg} \cdot \mathrm{Chl} \cdot \mathrm{g}^{-1}$ leaf) was recorded in plots those were fertilized in pellet $\left(\mathrm{T}_{3}\right)$ followed by $\mathrm{T}_{2}(\mathrm{~N}$ fertilizer) with 0.87 $\mathrm{mg} \cdot \mathrm{Chl} \cdot \mathrm{g}^{-1}$ leaf. The minimum plant $\mathrm{Chl}$ content $(76$ $\mathrm{mg} \cdot \mathrm{Chl} \cdot \mathrm{g}^{-1}$ leaf) was recorded from plot where no fertilizer and pellet was applied $\left(\mathrm{T}_{1}\right)$ (Figure 5).

Total weight of plant is one of the important factors contributing to crop yield. Data regarding total weight are given Figure 6. It was clear from the figure that total weight was significantly affected by different proportion of $\mathrm{N}$ fertilizers. The comparison of individual treatments' means indicated that maximum total weight was recorded

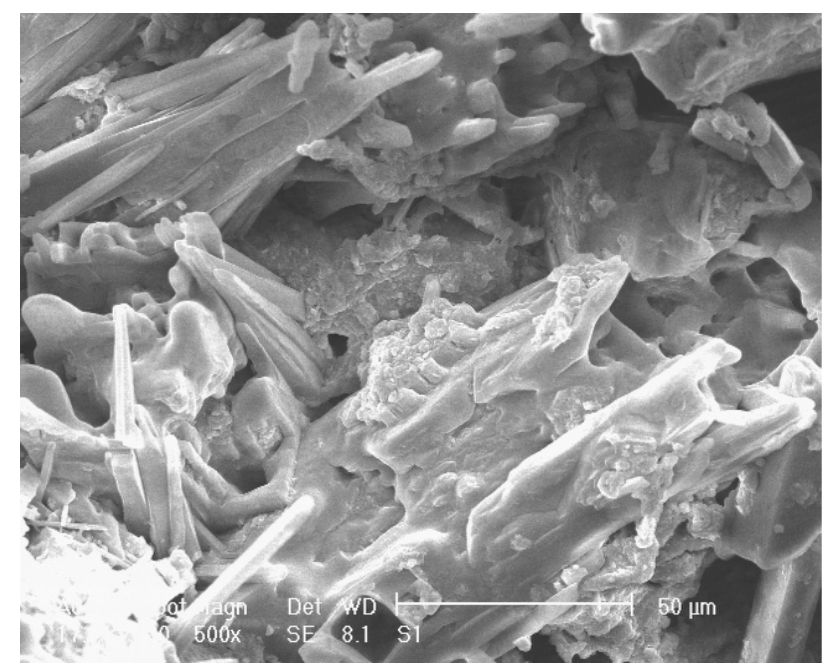

Figure 4. Solid bridges and mechanical interlocking bonds between compost and urea particles. 


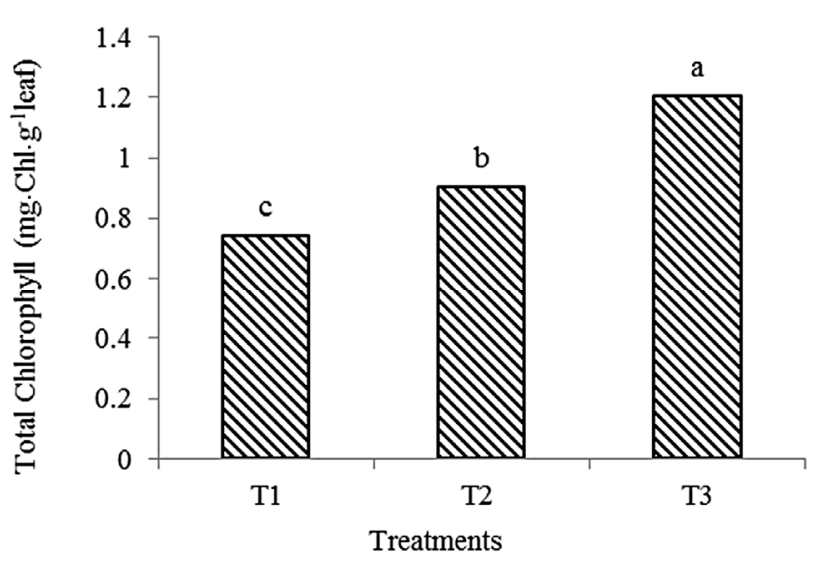

Figure 5. Response of chlorophyll to different treatments.

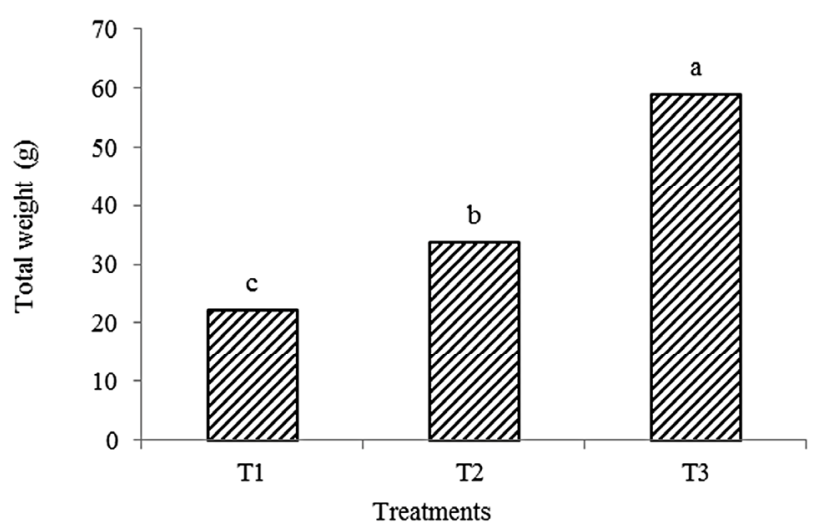

Figure 6. Response of total weight to different treatments.

in pellet treatment. The increase in plant total weight in case of $50 \%$ urea $+50 \%$ composted cow manure was mainly due to the more availability of nitrogen throughout the growing period.

The effect of changes in total weight was investigated. From the first growth stage to 6 weeks after sowing little difference between $\mathrm{T}_{2}$ and $\mathrm{T}_{3}$ was found however difference increasing rapidly in the final four weeks (Figure 7). Slow release of nitrogen and provide the nitrogen needed for plant in the end period of growth is reason for this.

A significant difference among the nitrogen treatments was found on the weight of leaves $(\mathrm{P}<0.01)$. The highest weight of leaves was obtained at pellet application while the least leaf weight was obtained in the control (Figure 8). Takebe et al. (1995) reported that increments in leaf weight may be due to a combination of nitrogen with plant matter produced during photosynthesis such as glucose, ascorbic acid, amino acids and protein [27]. Also, Tei et al. (2000) reported that increasing the rate of nitrogen fertilizer significantly increased the weight of leaves [28]. In the first stages of growth there was a small increase in the rate of weight formation but by increasing plant growth and leaf area the amount of matter increased proportionally (Figure 9).

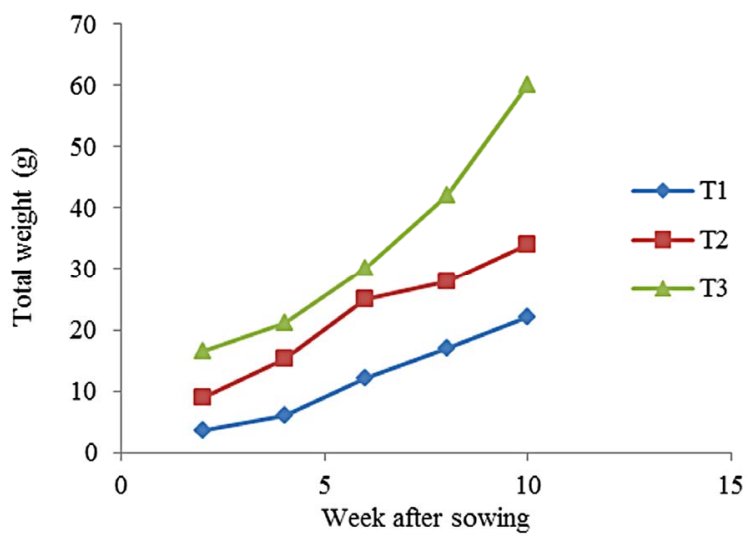

Figure 7. Change of total weight in during period of growth.

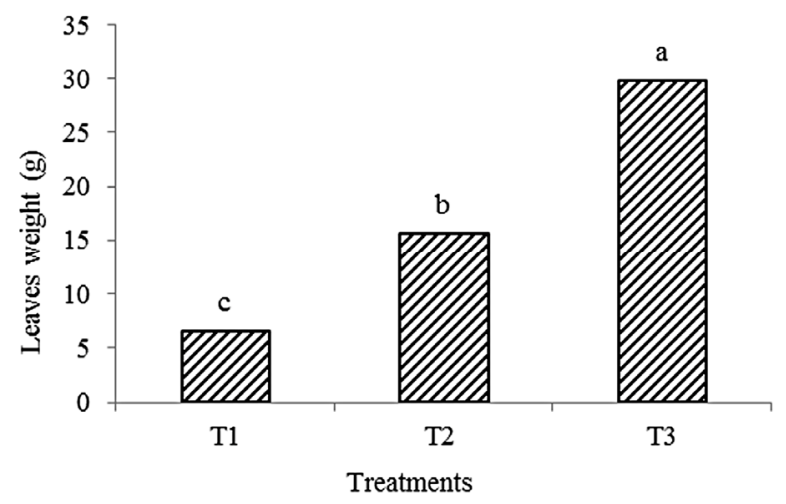

Figure 8. Response of leaves weight to different weight.

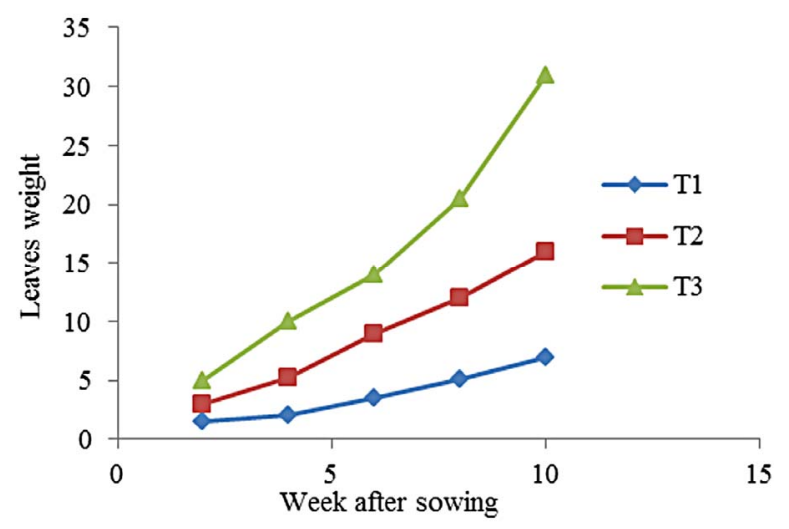

Figure 9. Change of leaves weight in during period of growth.

The mean data showed a significant difference in root weight due to nitrogen doses (Figure 10). The results showed that root weight in pellet fertilizer treatment was higher than other treatments clearly. Karrou and Maranvill investigated the responses of wheat cultivar to different soil nitrogen and moisture regimes and concluded that effect of nitrogen on root grow may be positive or negative that depending on the nitrogen concentration at the root surface [29]. $\mathrm{N}$ leaching is factor that causes $\mathrm{N}$ fertilizer provide nitrogen needed for plants in the first 
stages of growth therefore in the end period of growth root weight increase slowly (Figure 11).

The yield of a green plant is a function of its photosynthetic area. The leaf area is an important parameter that influences the photosynthesis. The effect of nitrogen fertilizer level on leaf area was significant at $\mathrm{P}<0.01$ (Figure 12). The effect of different nitrogen levels on leaf area showed that in the first stages of growth leaf area was low but gradually, by increasing leaves' growth, the leaf area increased and the difference between treatments could be assessed (Figure 13).

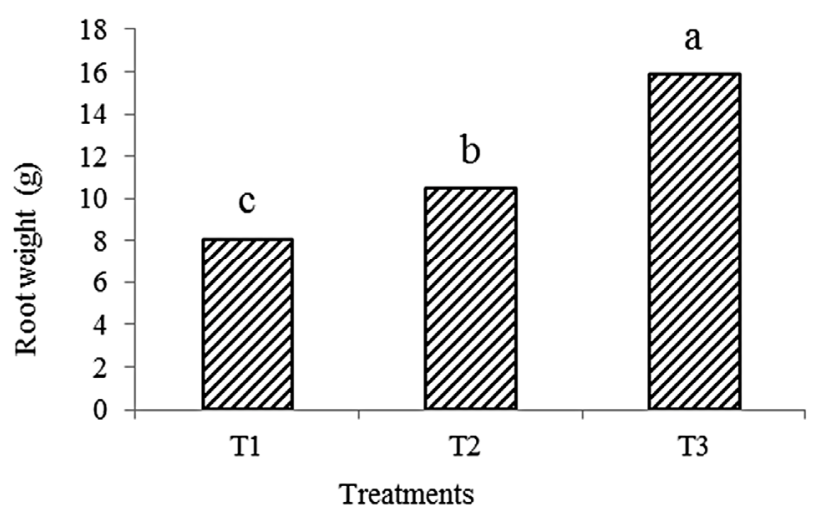

Figure 10. Response of root weight to different treatment.

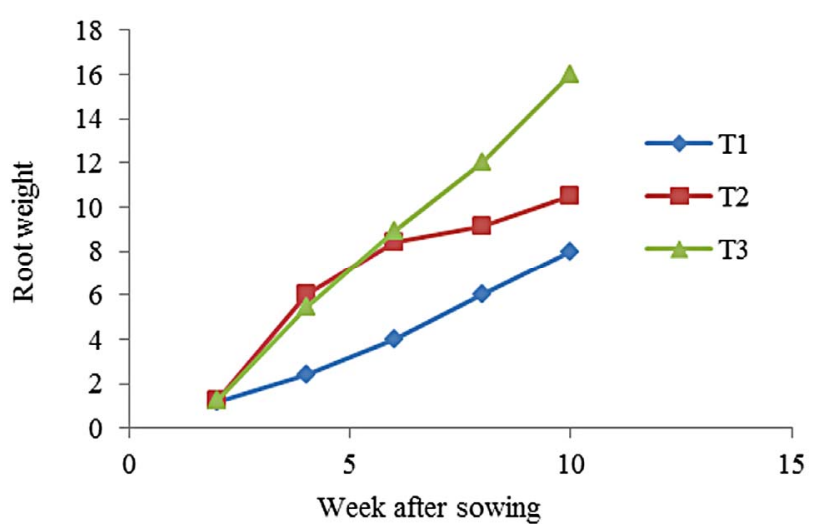

Figure 11. Change of root weight in during period of growth.

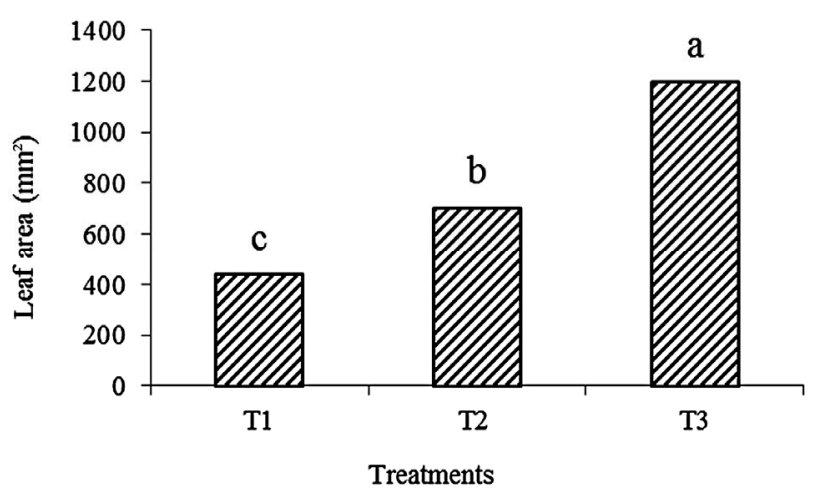

Figure 12. Response of leaf area to different treatment.

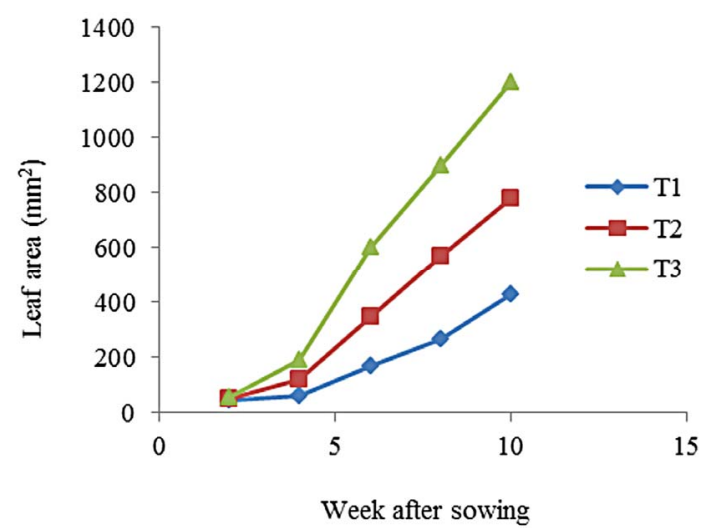

Figure 13. Change of leaf area in during period of growth.

The comparison of treatments' means between $\mathrm{N}$ fertilizer and control treatments indicate that nitrogen is an effective material for improving the crop production however comparison of treatments' means between $\mathrm{N}$ fertilizer and pellet treatments revealed is important that nitrogen is available for plants in throughout the growing period. The observation showed that pellet fertilizer can release the nitrogen and other nutrients slowly in throughout the growing period.

The results of this study was in agreement with the results from study by Bagheri et al. (2011) that evaluated the effect of slow-release of nitrogen from livestock manure and urea pellet on some physiological and morphological characteristics of corn grain [30]. Also Alemi et al. (2010) observed the effect of mixed pellet on slowrelease nitrogen and yield improving of wheat [31]. Fernández et al. (2004) studied the effect of traditional and slow-release $\mathrm{N}$ fertilizers on growth of olive nursery plants and $\mathrm{N}$ losses by leaching; they reported that total $\mathrm{N}$ losses were lower with the slow-release fertilizers [32].

\section{Conclusion}

In this study the single screw extruder was used to produce compound fertilizer pellets including composted cow manure and urea. The density of produced pellets was increased significantly, which is very important for reduction transport and application costs. The pellet fertilizer provided a gradual nutrient supply for a long period of time, which improves $\mathrm{N}$ fertilizer use efficiency and reduces $\mathrm{N}$ leaching losses. Slow-release fertilizers can be useful tools in calibrating the availability of $\mathrm{N}$ fertilizer to plant demands and in reducing the risk of $\mathrm{N}$ fertilizer loss by leaching. Due to the high consumption of nitrogen fertilizers in Iran, costs associated with the manufacture and distribution of nitrogen fertilizer, devastating impact of nitrogen fertilizer on the soil and high manure produced in Iran, the use of compound fertilizer pellet is a proper way for livestock manure management and reduction nitrogen fertilizer consumption. 


\section{REFERENCES}

[1] D. Tilman, K. G. Cassman, P. A. Matson, R. Naylor and S. Polasky, "Agricultural Sustainability and Intensive Production Practices," Nature, Vol. 418, No. 6898, 2002, pp. 671-677. doi:10.1038/nature01014

[2] P. Matson, R. Naylor and I. Ortiz-Monasterio, "Integration of Environmental, Agronomic, and Economic Aspects of Fertilizer Management," Science, Vol. 280, No. 5360, 1998, pp. 112-115.

doi:10.1126/science.280.5360.112

[3] J. N. Galloway, et al., "The Nitrogen Cascade," BioScience, Vol. 53, No. 4, 2003, p. 341. doi:10.1641/0006-3568(2003)053[0341:TNC]2.0.CO;2

[4] V. T. Rymar, A. C. Udzhurkhu, V. D. Parkhomenko, A. A. Pivovarov, V. K. Steba and E. S. Smirnova, "Effect of Different Forms of Nitrogen Fertilizers on Rice Yield," Fiziologiya i Biokhimiya Kul'turnykh Rastenii, Vol. 21, 1989, pp. 97-101.

[5] J. E. Eriksson, "Effects of Nitrogen-Containing Fertilizers on Solubility and Plant Uptake of Cadmium," Water, Air, and Soil Pollution, Vol. 49, No. 3-4, 1990, pp.355-368. doi:10.1007/BF00507075

[6] M. A. Ahmed, M. Z. Nabila and M. S. Hassanein, "Response of Grain Sorghum to Different Nitrogen Sources," Response of Grain Sorghum to Different Nitrogen Sources, Vol. 3, No. 6, 2007, pp. 1002-1008.

[7] J. R. Freney, C. J. Smith and A. R. Mosier, "Effect of a New Nitrification Inhibitor (Wax Coated Calcium Carbide) on Transformations and Recovery of Fertilizer Nitrogen by Irrigated Wheat," Fertilizer Research, Vol. 32, No. 1, 1992, pp. 1-11.

[8] C. Chang, T. G. Sommerfeldt and T. Entz, "Soil Chemistry after Eleven Annual Applications of Cattle Feedlot Manure," Journal of Environmental Quality, Vol. 20, No. 2, 1991, pp. 475-480. doi:10.2134/jeq1991.00472425002000020022x

[9] B. Eghball, "Soil Properties as Influenced by Phosphorusand Nitrogen-Based Manure and Compost Applications," Agronomy Journal, Vol. 94, No. 1, 2001, pp. 128-135. doi:10.2134/agronj2002.0128

[10] L. M. Mugwira, "Residual Effects of Dairy Manure on Millet and Rye Forage and Soil Properties," Journal of Environmental Quality, Vol. 8, No. 2, 1979, pp. 251-255. doi:10.2134/jeq1979.00472425000800020024x

[11] G. W. Wallingford, L. S. Murphy, W. L. Powers and H. L. Manges, "Disposal of Beef-Feedlot Manure: Effects of Residual and Yearly Applications on Corn and Soil Chemical Properties," Journal of Environmental Quality, Vol. 4, No. 4, 1975, pp. 526-531. doi:10.2134/jeq1975.00472425000400040021x

[12] C. A. Holley, "The Densification of Biomass by Roll Briquetting," Proceedings of the Institute for Briquetting and Agglomeration (IBA), Vol. 18, 1983, pp. 95-102.

[13] S. Mani, L. G. Tabil and S. Sokhansanj, "An Overview of Compaction of Biomass Grinds," Powder Handling and Processing, Vol. 15, 2003, pp. 160-168.

[14] I. Obernberger and G. Thek, "Physical Characterisation and Chemical Composition of Densified Biomass Fuels with Regard to Their Combustion Behavior," Biomass and Bioenergy, Vol. 27, No. 6, 2004, pp. 653-669. doi:10.1016/j.biombioe.2003.07.006

[15] J. McMullen, O. O. Fasina, C. W. Wood and Y. Feng "Storage and Handling Characteristics of Pellets from Poultry Litter," Applied Engineering in Agriculture, Vol. 21, No. 4, 2005, pp. 645-651.

[16] J. K. Holm, U. B. Henriksen, J. E. Hustad and L. H. Sorensen, "Toward an Understanding of Controlling Parameters in Softwood and Hardwood Pellets Production," Energy Fuel, Vol. 20, No. 6, 2006, pp. 2686-2694. doi:10.1021/ef0503360

[17] N. Kalyan and R. V. Morey, "Factors Affecting Strength and Durability of Densified Biomass Products," Biomass Bioenergy, Vol. 33, No. 3, 2009, pp. 337-359. doi:10.1016/j.biombioe.2008.08.005

[18] M. Hara, "Fertilizer Pellets Made from Composted Livestock Manure," Agriculture Research Division Mie Prefectural Science and Technology Promotion Center, Kansai, 2001.

[19] J. A. Moran, A. K. Mitchell, G. Goodmanson and K. A. Stockburger, "Differentiation among Effects of Nitrogen Fertilization Treatments on Conifer Seedlings by Foliar Reflectance: A Comparison of Methods," Tree Physiology, Vol. 20, No. 16, 2000, pp. 1113-1120. doi:10.1093/treephys/20.16.1113

[20] T. Winowiski, "Wheat and Pellet Quality," Feed Management, Vol. 39, 1988, pp. 58-64.

[21] J. L. Briggs, D. E. Maier, B. A. Watkins and K. C. Behnke, "Effects of Ingredients and Processing Parameters on Pellet Quality," Poultry Science, Vol. 78, No. 10, 1999, pp. 1464-1471.

[22] J. F. Wood, "The Functional Properties of Feed Raw Materials and Their Effect on the Production and Quality of Feed Pellets," Animal Feed Science Technology, Vol. 18, No. 1, 1987, pp. 1-17. doi:10.1016/0377-8401(87)90025-3

[23] N. Kalyan and R. V. Morey, "Factors Affecting Strength and Durability of Densified Biomass Products," Biomass Bioenergy, Vol. 33, No. 3, 2009, pp. 337-359. doi:10.1016/j.biombioe.2008.08.005

[24] H. Rumpf, "The Strength of Granules and Agglomeration," In: W. A. Knepper, Ed., Agglomeration, John Wiley, New York, 1962, pp. 379-418.

[25] W. Pietsch, "Agglomeration Processes-Phenomena, Technologies, Equipment," Wiley-VCH, Weinheim, 2002.

[26] L. Tabil Jr. and S. Sokhansanj, "Process Conditions Affecting the Physical Quality of Alfalfa Pellets," Applied Engineering in Agriculture, Vol. 12, No. 3, 1996, pp. 345-350.

[27] M. Takebe, T. Ishihara, K. Matsuna, J. Fojimoto and T. Yoneyama, "Effect of Nitrogen Application on the Content Sugars, Ascorbic Acid, Nitrate And Oxalic Acid in Spinach (Spinacia oleracea L.) and Kamatsuna (Nrasica compestris L.)," Japanese Journal of Soil Science and Plant Nutrition, Vol. 66, 1995, pp. 238-246.

[28] F. Tei, P. Benincasa and M. Guiducci, "Effect of Nitrogen 
Availability on Growth and Nitrogen Uptake in Lettuce," Acta Horticulturae, Vol. 533, 2000, pp. 385-392.

[29] M. Karrou and J. W. Maranvill, "Responses of Wheat Cultivar to Different Soil Nitrogen and Moisture Regimes, Dry Matter Petitioning and Root Growth," Journal of Plant Nutrition, Vol. 17, No. 5, 2003, pp. 729-744. doi:10.1080/01904169409364763

[30] R. Bagheri, G. A. Akbari, M. H. Kianmehr, Z. A. Tahmasbi and M. Younessi, "The Effect of Pellet Fertilizer Application on Corn Yield and Its Components," African Journal of Agricultural Research, Vol. 6, No. 10, 2011, pp. 2364-2371.

[31] H. Alemi, M. H. Kianmehr and A. M. Borghaee, "Effect of Pellet Processing on Slow-Release Nitrogen in Soil," Asian Journal of Plant Science, Vol. 9, No. 2, 2010, pp. 74-80. doi:10.3923/ajps.2010.74.80

[32] R. Fernández-Escobar, M. Benlloch, et al., "Effect of Traditional and Slow-Release N Fertilizers on Growth of Olive Nursery Plants and N Losses by Leaching," Scientia Horticulturae, Vol. 101, No. 1-2, 2004, pp. 39-49. doi:10.1016/j.scienta.2003.09.008 